\title{
Identification of proteins related to the stress response in Enterococcus faecalis V583 caused by bovine bile
}

\author{
Liv Anette Bøhle1, Ellen M Færgestad², Eva Veiseth-Kent², Hilde Steinmoen' ${ }^{1}$, Ingolf F Nes ${ }^{1}$, Vincent GH Eijsink ${ }^{1}$ and \\ Geir Mathiesen*1
}

\begin{abstract}
Background: Enterococcus faecalis is an opportunistic pathogen and one of the most important causes of hospital infections. Bile acids are a major stress factor bacteria have to cope with in order to colonize and survive in the gastrointestinal tract. The aim of this study was to investigate the effects of bile acids on the intracellular proteome of $E$. faecalis V583.

Results: The proteomes of cells challenged with 1\% bile were analyzed after 20 - 120 minutes exposure, using 2D gel electrophoresis and mass spectrometry. Among the approximately 500 observed proteins, 53 unique proteins were found to be regulated in response to bile and were identified with mass spectrometry. The identified proteins belonged to nine different functional classes, including fatty acid- and phospholipid-biosynthesis, energy metabolism, and transport and binding. Proteins involved in fatty acid and phospholipid biosynthesis pathways were clearly overrepresented among the identified proteins and all were down-regulated upon exposure to bile. The proteome data correlated reasonably well with data from previous transcriptome experiments done under the same conditions, but several differences were observed.

Conclusion: The results provide an overview of potentially important proteins that E. faecalis $V 583$ needs to regulate in order to survive and adapt to a bile-rich environment, among which are several proteins involved in fatty acid and phospholipid biosynthesis pathways. In addition, this study reveals several hypothetical proteins, which are both abundant and clearly regulated and thus stand out as targets for future studies on bile stress.
\end{abstract}

\section{Background}

Enterococcus faecalis is a wide-spread Gram-positive lactic acid bacterium, and is a natural inhabitant of the gastrointestinal tract (GIT) of humans and animals. The bacterium is also commonly found in soil, sewage, water and food. E. faecalis V583 is an opportunistic pathogen that can cause diseases like urinary tract infections, bacteremia, and infective endocarditis in immunocompromised patients. These infections may be problematic because $E$. faecalis strains tend to be resistant toward many antibiotics, including vancomycin $[1,2]$. Vancomycin-resistant enterococci were first found among clinical isolates in the late 1980s, and antibiotic resistance has

* Correspondence: geir.mathiesen@umb.no

1 Department of Chemistry, Biotechnology and Food Science, Norwegian University of Life Sciences, Chr. M. Falsensvei 1, N-1432 Ås, Norway Full list of author information is available at the end of the article increased since. Infections by enterococci have become a major problem in the hospital environments and enterococci are now ranked among the most prevalent nosocomial pathogens $[3,4]$.

E. faecalis is able to grow and colonize many hostile environments including the GIT, and is considered as an interesting model for studying bacterial stress responses [5]. It is important to understand such responses in enterococci because the ability to survive in a wide range of environments obviously contributes to enterococcal prevalence in e.g. hospital environments. In order to survive in the human GIT, bacteria must overcome several adverse environmental stresses such as low $\mathrm{pH}$, low oxygen levels, nutrient limitations, elevated osmolarity and the deleterious actions of bile. The liver daily secretes about one liter of bile, which consists mainly of bile acids, 
cholesterol, phospholipids, and the pigment biliverdin. In the human GIT, bile acts as a biological detergent, emulsifying and solubilising fats [6]. Exposure to bile may lead to changes in the fatty acid- and phospholipid-composition of bacterial membranes and to distortion of the cell surface $[7,8]$. It has also been shown that bile can induce secondary structure formation in RNA, induce DNA damage and activate enzymes involved in DNA repair [6].

Various studies indicate that bacteria thriving in the GIT, such as lactic acid bacteria and bifidobacteria, have evolved mechanisms to protect themselves from the noxious effects of bile. Genome-wide and gene-by-gene studies have shown that Gram-positive bacteria such as listeria, lactobacilli and bifidobacteria carry genes coding for transporters able to extrude bile salts, the expression of which is regulated by bile salts [9-11]. Additional genes whose expression is regulated by bile include genes involved in more general stress responses and genes involved in carbohydrate metabolism and fatty acid biosynthesis [12-15].

While genome and transcriptome analyses have provided interesting clues as to how enterococci manage bile stress, so far, proteome information is limited [16-18]. Since transcriptome and proteome data do not necessarily correlate, knowledge of proteome responses is a prerequisite for obtaining a more complete picture of the bile salt response. Therefore, we have analyzed how the intracellular proteome of E. faecalis V583 responds to bovine bile in a time course experiment, assessing both immediate responses and longer term effects. We used twodimensional- (2D) gel electrophoresis combined with mass spectrometry-based protein identification to identify the bacterial proteins whose abundances change during growth in presence of $1 \%$ bovine bile. The experiments were conducted using conditions identical to those used in a previous transcriptome study on bile stress [15] permitting comparison of proteome and transcriptome data.

\section{Materials and methods}

\section{Bacterial strain and sample collection}

E. faecalis V583 [19] was grown in brain heart infusion (BHI) medium (Oxoid Ltd., Hampshire, England) aerobically, over-night, with shaking, $300 \mathrm{rpm}$, at $37^{\circ} \mathrm{C}$. The over-night cultures $(50 \mathrm{ml})$ were diluted 50 -fold in $100 \mathrm{ml}$ $\mathrm{BHI}\left(37^{\circ} \mathrm{C}\right)$ and grown further to an OD ${ }_{600}$ of $\sim 0.2$, after which the cells were collected by centrifugation $(9800 \times \mathrm{g}$, $10 \mathrm{~min}$, at room-temperature). After resuspending the cells in $50 \mathrm{ml}$ of fresh prewarmed $\mathrm{BHI}\left(37^{\circ} \mathrm{C}\right)$ another 50 $\mathrm{ml}$ of prewarmed BHI-medium with or without bovine bile (Sigma-Aldrich Inc, St. Louis, MO) was added. Thus, the final volume was $100 \mathrm{ml}$ for each condition and the final concentration for the samples with bovine bile was
$1 \%(\mathrm{w} / \mathrm{v})$. The cultures were incubated with shaking, 300 $\mathrm{rpm}$, at $37^{\circ} \mathrm{C}$, until harvesting. After incubation for 20,60 or 120 minutes cells were harvested from the cultures by centrifugation $\left(9800 \times \mathrm{g}, 10 \mathrm{~min}, 4^{\circ} \mathrm{C}\right)$. The cell pellets were washed three times with ice-cold $0.9 \%(\mathrm{w} / \mathrm{v}) \mathrm{NaCl}$, and subsequently resuspended in a lysis- and rehydration-solution containing $8 \mathrm{M}$ urea, $2 \mathrm{M}$ thiourea, $50 \mathrm{mM}$ DTT and 2\% CHAPS. The cells were disrupted with glass-beads (106 micron, Sigma-Aldrich) using a FastPrep-24 instrument (MP Biomedicals, Solon, OH) (speed 6 , three treatments of 45 seconds each, with 60 second pauses in between, at $4^{\circ} \mathrm{C}$ ). The resulting cell-free extracts were stored at $-20^{\circ} \mathrm{C}$ until the $2 \mathrm{D}$ analyses were performed (see below). The protein concentration of the cell-free extracts was measured using the Bradford Microassay (Bio-Rad Laboratories, Inc, Hercules, CA).

To check the effect of bile on the growth rate of $E$. faecalis V583, the bacteria were grown in liquid BHI with or without $1 \%$ bile, at $300 \mathrm{rpm}, 37^{\circ} \mathrm{C}$. The growth was followed by measuring the optical density $\left(\mathrm{OD}{ }_{600}\right.$ ) of the cultures every 20 minutes in the first 3 hours, and then every 30 minutes.

\section{Two-dimensional gel electrophoresis and analysis}

Isoelectric focusing (IEF) was performed using $24 \mathrm{~cm}$ IPG-strips (Bio-Rad) covering the $\mathrm{pH}$-area 4-7. The cellfree protein sample was diluted in a lysis-and rehydration-solution together with ampholytes in a total volume of $450 \mu \mathrm{l}$, containing $75 \mu \mathrm{g}$ proteins. This protein-sample was loaded on the strips, and rehydration was performed for 16 hours at $50 \mathrm{~V}$ using a Protean IsoElectric Focusing Cell II unit (Bio-Rad). Then, isoelectric focusing was carried out using the following voltage program: a linear ramp to $250 \mathrm{~V}$ over 30 minutes, followed by a rapid ramp to $500 \mathrm{~V}$ over 1 hour, a rapid ramp to $1000 \mathrm{~V}$ over 1 hour, and then a rapid ramp to $10000 \mathrm{~V}$, where the voltage is fixed until the total reached $70000 \mathrm{Vh}$.

To prepare for electrophoresis in the second dimension, the IPG-strips were first equilibrated in a buffer containing $6 \mathrm{M}$ urea, $50 \mathrm{mM}$ Tris- $\mathrm{HCl} \mathrm{pH} 8.8,30 \%$ glycerol, 2\% SDS and 1\% dithiothreitol (DTT) for 15 minutes to reduce sulfhydryl groups, and then in a buffer containing $6 \mathrm{M}$ urea, $50 \mathrm{mM}$ Tris- $\mathrm{HCl} \mathrm{pH} 8.8,30 \%$ glycerol, $2 \%$ SDS and 5\% iodoacetamide for an additional 15 minutes to alkylate the reduced sulfhydryl groups. Subsequently, the strips were loaded onto a $12.5 \%$ SDS-gel for the SDSPAGE step. The electrophoresis was run at $5 \mathrm{mAmp} / \mathrm{gel}$ for 3 hours and then at $15 \mathrm{mAmp} /$ gel for 12 hours. Normally, 12 gels were run simultaneously, using an EttanDALT Electrophoresis system (Amersham Biosciences, USA). The gels were silver stained according to a previously described method [20]. 
For each growth condition/time point (six combinations in total), five biological replicates were produced. These 30 samples were run twice through the 2D-electrophoresis, yielding a total of 60 gels. Spot detection and gel alignment were performed using Delta2D software (DECODON, Greifswald, Germany). In this method all pixels are compiled into a fused image that is used for setting common spot boundaries for all gel samples, whereas the raw data for the spot intensities are obtained from each individual image [21]. All proteins were visually checked and only spots that did not appear as streaking were included (this procedure was repeated after preselection of regulated proteins; see Results section). In the further analyses only spots showing a fold change of at least 1.9 (with bile versus without bile) at at least one time point were included. This somewhat arbitrary threshold value is comparable to the threshold factors used in other studies [22,23]. Lower threshold factors were not considered in order to maximize the chance that the discovered changes in protein levels are not only statistically but also biologically significant. Based on this criterion, 115 spots were selected and subjected for statistical analysis. Analysis of variance was performed where the p-values were adjusted for multiple comparisons by False Discovery Rate (FDR) using rotation test $[24,25]$ with a significance level of $\mathrm{p}<0.05$. Upon this procedure, the number of spots was reduced to 91 .

\section{Protein identification}

Spots representing differently expressed proteins were excised from the gel and the gel pieces were washed $2 \times$ 15 minutes with a 1:1 mixture of acetonitrile $(\mathrm{ACN})$ and $50 \mathrm{mM}$ ammonium bicarbonate. The gel-pieces were dried in a speed-vac and the dried gel-pieces were reswollen with $0.03 \mu \mathrm{g} / \mu \mathrm{l}$ trypsin at $4^{\circ} \mathrm{C}$ for 30 minutes (approximately $5 \mu \mathrm{l}$ on average). Subsequently, $25 \mu \mathrm{l} 50$ $\mathrm{mM}$ ammonium bicarbonate was added, and the digestion of proteins was performed by incubating overnight at $37^{\circ} \mathrm{C}$ with shaking at $300 \mathrm{rpm}$. The peptides were extracted from the gel-pieces by incubating the pieces in $1 \%$ trifluoroacetic acid (TFA), $0.1 \%(\mathrm{v} / \mathrm{v})$ TFA in $50 \%(\mathrm{v} / \mathrm{v})$ $\mathrm{ACN}$, and $100 \% \mathrm{ACN}$, in three consecutive steps. The liquid phases were pooled and the extracted peptides were dried in a speed-vac, rehydrated in $0.1 \%(\mathrm{v} / \mathrm{v})$ TFA, and sonicated prior to desalting using C18 STAGE tips [26]. After eluting the peptides with $1 \mu \mathrm{l} 65 \%$ (v/v) ACN, $0.5 \mu \mathrm{l}$ of the eluate was mixed with $0.5 \mu \mathrm{l}$ matrix solution $(\alpha-$ cyano-4-hydroxycinamic acid), and spotted onto a MALDI target plate (Bruker Daltonics, Billerica, MA).

Peptide mass fingerprints (PMF) and MS/MS fragmentation spectra were determined using an UltraflexMALDI-TOF/TOF (Bruker Daltonics) instrument. Protein identification was carried out with Mascot (Matrix Science Inc., Boston, MA), limiting the search to bacteria belonging to the "Other Firmicutes" in the NCBI database. The searches were limited to only consider tryptic fragments, with carbamidomethylation of cysteine (fixed modification) and possible oxidation of methionine. The error tolerance was set to $50 \mathrm{ppm}$, and the number of allowed missed cleavage sites was set to 2 .

Some proteins giving weak spots could not be identified by MALDI-TOF/TOF. These proteins were analyzed by Nano LC coupled to ESI-MS/MS, using an LC-LTQ Orbitrap-MS at The Biotechnology Centre of Oslo, Norway.

\section{Results}

The effect of bovine bile on the growth rate of E. faecalis V583 was tested by comparing growth in the absence and presence of $1 \%(\mathrm{w} / \mathrm{v})$ bovine bile in liquid BHI medium (Fig. 1). The growth curves showed that the presence of bile reduces both the growth rate and the maximum cell density, but also showed that the levels of bile used in this study are clearly sub-lethal, permitting accumulation of sufficient cells in the samples with bile. Cells were harvested at 20,60 and 120 minutes after the addition of bile.

Additional file 1 shows six representative gels from the 2D-gel electrophoresis experiments, one gel for each time point at each condition (presence or absence of bile). Visual inspection of the about 500 distinguishable spots on the gels showed some clear differences between the bile and non-bile samples. The data-set used for image analysis and identification of differentially expressed proteins was obtained from 60 gels. These gels represented five biological replicates for each growth condition/time point (30 samples in total), which were run twice. Statistical validation was performed based on the pixel values for

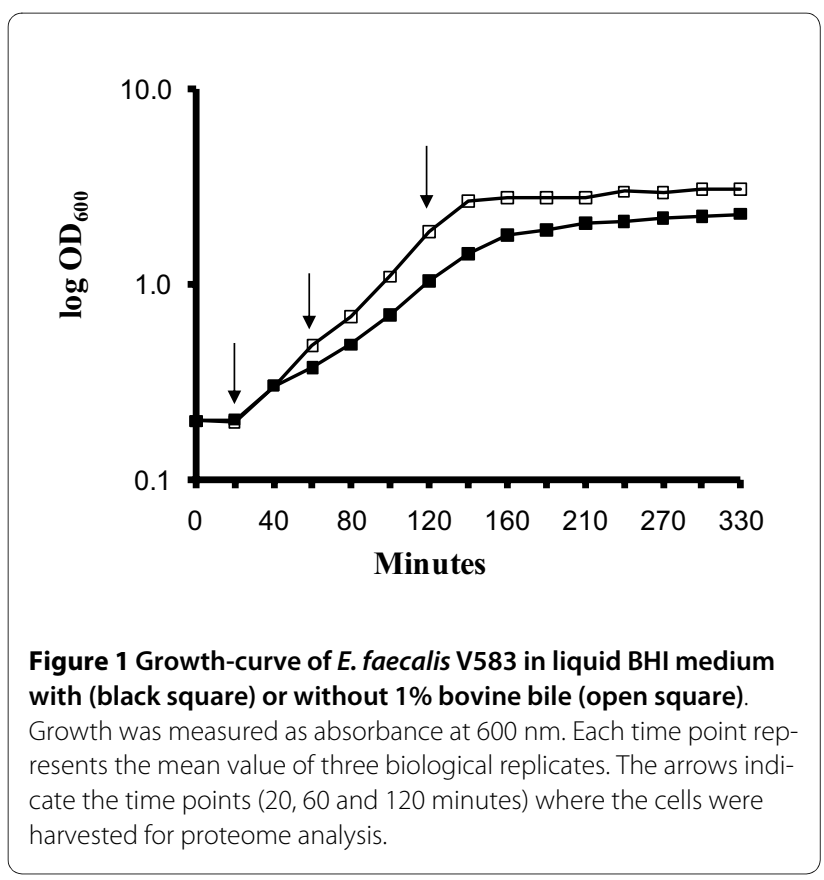


each protein spot. In total 91 spots met the two criteria of (1) showing significant changes according to the FDR adjusted p-value $(<0.05)$ and $(2)$ showing an increase or decrease of at least 1.9-fold in response to bile at at least one of the three time points. The 91 spots were visually controlled in more detail and proteins that appeared as streaking were removed from the analysis (32 spots; these are spots for which the image analysis is prone to errors). The resulting 59 spots were subjected to protein identification by mass spectroscopy. This analysis identified 55 proteins whose abundances were considered to change upon bile stress while four proteins could not be identified. Two proteins were identified twice: spot 16 and 19 were identified as formate acetyltransferase (EF1613), and spot 49 and 51 were identified as ribose-phosphate pyrophosphokinase (EF3163). In both cases, the two protein spots belonging to the same protein represented different masses and pI. Such differences may be explained by one of the spots being a proteolytic fragment or carrying another type of post-translational modification. Within each pair, the spots showed similar trends in terms of the change in protein abundance.

Of the 53 identified unique proteins, 17 were up-regulated, 32 were down-regulated, and four were both upand down-regulated during the time course experiment (Table 1). The number of regulated proteins increased during the time course experiment, from eight after 20 minutes, to 21 after 60 minutes, to 38 after 120 minutes (Table 1). Only 14 proteins showed significantly altered abundances at more than one time point, indicating that the observed up- and down-regulations are relatively transient. Among the 53 unique proteins, 14 are annotated in the J. Craig Venter Institute (JCVI) Comprehensive microbial resource as hypothetical proteins or proteins with unknown functions (Table 1). The other 39 proteins belong to nine different functional classes (Table 1). Proteins involved in energy metabolism and in the transcription-translation process were most abundant, with eight and nine identified proteins in each functional class, but their relative abundance was comparable with that of proteins in most of the other functional classes (Fig. 2). These two most numerous groups did not show clear overall trends with respect to up- or down-regulation. Proteins involved in fatty acid and phospholipid metabolism were clearly overrepresented among the identified proteins (Fig. 2) and all of these were downregulated by the presence of $1 \%$ bovine bile (Fig. 3 ). The rest of the identified proteins are predicted to be involved in processes related to protein fate, transport and binding, nucleotide metabolism, coenzyme transport and metabolism, amino acid biosynthesis, and cell wall/membrane biogenesis, as well as in "other cellular processes" related to bacterial adaptation to atypical conditions.
The growth conditions used in the present proteome study were similar to those used in a previous transcriptome study with the same bacterium [15]. The expression profiles from the transcriptome study [15] were compared with the data from the present study for the 19 proteins that were found to be significantly regulated in both studies (Fig. 4). While the expression profiles derived from the two methods show the same tendencies for about eleven of these 19 proteins, discrepancies are observed in several cases, either at one time point (e.g. EF0020 \& EF1499 at 120 minutes) or in the form of an overall trend (e.g. EF3184 and EF3186 where an increase in transcription does not seem to lead to an increase in protein).

\section{Discussion}

In the present study we used 2D gel electrophoresis to identify proteins in E. faecalis V583 whose levels are regulated in response to bile. The cells were analysed at three different time points. By using this set up both the initial and more long-term effects of bile could be observed.

The gels showed approximately 500 spots, which is $20 \%$ of the intracellular proteome of E. faecalis V583. Use of visual inspection, a threshold fold ratio of 1.9 , and rigorous statistical analysis led to the identification of 53 unique proteins that are regulated in response to bile stress, representing about $10 \%$ of the proteins on the gels. This number of regulated proteins is higher than what has been obtained in similar proteomic studies in other Gram-positive bacteria. Previous studies have identified 28 proteins in Lactobacillus reuteri [27], 24 proteins in Propionibacterium freudenreichii [22], 45 proteins in Bifidobacterium animalis [28], and 34 proteins in Bifidobacterium longum [23]. The high number obtained in the present study may partly be due to the fact that we have studied the proteome in a time-course experiment, which, to the best of our knowledge, has not been done before in studies of bile responses in Gram-positive bacteria.

Bile stress in Enterococcus faecalis was among the first bacterial stress responses to be studied using the 2D electrophoresis approach. In an early study aimed at identifying stress-induced proteins, 45 protein spots were found to be up-regulated upon exposure to bile for 30 minutes [16]. Only two proteins, DnaK and GroEL, were identified and it is therefore difficult to compare this work with the present study (note that DnaK was also found to be upregulated in our study; see below). In a later study by Giard et al. [18], peptide sequences for four additional bile-induced proteins were presented which correspond to EF0453, a protein involved in hydrogen peroxide resistance, and to three hypothetical proteins (EF0770, EF1560, EF2798). None of these four proteins were found 
Table 1: Identified proteins of E. faecalis V583 whose abundance is affected by the presence of $1 \%$ bovine bile-the three columns to the right show the results for cells harvested at three different time points $(20,60$ and 120 minutes)

\begin{tabular}{|c|c|c|c|c|c|c|c|c|c|c|}
\hline $\begin{array}{l}\text { Spot } \\
\text { no. }\end{array}$ & Functional class $^{a}$ & Putative function $^{a}$ & ORF & Mass (kDa) & $\mathrm{pl}^{b}$ & Coverage $^{c}$ & $\begin{array}{l}\text { No. of peptides } \\
\text { matched }\end{array}$ & \multicolumn{3}{|c|}{$\begin{array}{c}\text { Fold ratiod }^{d} \\
T(20) T(60) T(120)\end{array}$} \\
\hline $1^{e}$ & $\begin{array}{c}\text { Fatty acid and } \\
\text { phospholipid metabolsim }\end{array}$ & Enoyl-(acyl carrier protein) reductase & EF0282 & 26.9 & 5.29 & 42 & 14 & 1.01 & 0.67 & 0.3 \\
\hline $2^{e}$ & & $\begin{array}{l}\text { Acetyl_coA carboxylase, biotin carboxyl } \\
\text { carrier protein }\end{array}$ & EF2879 & 17.6 & 4.23 & 40 & 8 & 0.92 & 0.39 & 0.28 \\
\hline $3^{e}$ & & $\begin{array}{l}\text { (3R)-hydroxymyristoyl-(acyl-carrier- } \\
\text { protein) dehydratase }\end{array}$ & EF0284 & 16.4 & 5.73 & 22 & 5 & 1.09 & 0.71 & 0.49 \\
\hline $4^{e}$ & & 3-oxoacyl-(acyl-carrier-protein) synthase II & EF0283 & 43.5 & 5.11 & 40 & 12 & 0.51 & 0.87 & 0.41 \\
\hline $5^{e}$ & & 3-ketoacyl-(acyl-carrier-protein) reductase & EF2881 & 26.1 & 5.92 & 35 & 10 & 1.70 & 0.37 & 0.55 \\
\hline 6 & $\begin{array}{l}\text { Transport and binding } \\
\text { protein }\end{array}$ & Phosphocarrier protein $\mathrm{HPr}$ & EF0709 & 9.3 & 4.92 & 13 & 11 & 0.99 & 0.70 & 0.52 \\
\hline $7^{e}$ & & $\begin{array}{c}\text { PTS system, mannose-specific IIAB } \\
\text { components }\end{array}$ & EF0020 & 35.5 & 5.11 & 50 & 22 & 1.62 & 3.06 & 0.90 \\
\hline 8 & & $\begin{array}{c}\text { peptide } A B C \text { transporter, ATP-binding } \\
\text { protein }\end{array}$ & EF0912 & 35.9 & 5.97 & 20 & 7 & 1.10 & 1,00 & 0.46 \\
\hline $9 e$ & Amino acid biosynthesis & Ornithine carbamoyltransferase & EF0105 & 38.1 & 5.02 & 18 & 5 & 1.03 & 0.64 & 3.48 \\
\hline $10^{e}$ & & Decarboxylase, putative & EF0634 & 71.96 & 5.14 & 47 & 29 & 0.52 & 1.21 & 1.86 \\
\hline 11 & Other cellular processes & Glutathione reductase & $\mathrm{EF} 3270$ & 49.6 & 5.23 & 21 & 10 & 2.42 & 0.96 & 0.87 \\
\hline 12 & & Dps family protein & EF3233 & 17.9 & 4.56 & 46 & 6 & 0.51 & 0.81 & 1.23 \\
\hline 13 & & General stress protein, putative & EF1744 & 20.5 & 4.61 & 31 & 6 & 0.88 & 0.66 & 0.52 \\
\hline 14 & & Cell division protein DivIVA & EF1002 & 26.6 & 4.53 & 62 & 16 & 0.61 & 1.21 & 3.5 \\
\hline $15^{e}$ & Energy metabolism & Deoxyribose-phosphate aldolase & EF0174 & 23.3 & 4.65 & 48 & 10 & 1.39 & 1.28 & 0.47 \\
\hline $16^{f}$ & & Formate acetyltransferase & EF1613 & 84.5 & 5.31 & 11 & 8 & 1.00 & 0.95 & 2.87 \\
\hline $17^{e}$ & & Fumarate reductase flavoprotein subunit & $\mathrm{EF} 2556$ & 53.8 & 5.26 & 10 & 6 & 0.86 & 1.57 & 2.26 \\
\hline 18 & & Phosphoglycerate mutase 1 & EF0195 & 26.0 & 5.09 & 41 & 11 & 0.87 & 1.13 & 0.36 \\
\hline $19^{f}$ & & Formate acetyltransferase & EF1613 & 84.7 & 5.31 & 14 & 11 & 0.94 & 1.21 & 2.09 \\
\hline $20^{e}$ & & V-type ATP synthase subunit B & EF1499 & 51.3 & 5.03 & 18 & 8 & 0.59 & 2.02 & 1.29 \\
\hline 21 & & Pyruvate kinase & EF1046 & 62.6 & 4.99 & 41 & 25 & 2.99 & 3.61 & 1.09 \\
\hline 22 & & Enolase & EF1961 & 46.5 & 4.56 & 54 & 22 & 1.46 & 0.98 & 0.45 \\
\hline 23 & & Thioredoxin & EF1405 & 11.7 & 4.35 & 66 & 9 & 1.49 & 0.40 & 0.60 \\
\hline $24^{e}$ & $\begin{array}{l}\text { Cell wall } / \text { membrane } \\
\text { biogenesis }\end{array}$ & D-fructose-6-phosphate amidotransferase & EF2151 & 65.7 & 4.93 & 24 & 12 & 1.93 & 1.13 & 2.12 \\
\hline 25 & $\begin{array}{l}\text { Coenzyme transport and } \\
\text { metabolism }\end{array}$ & Naphthoate synthase & EF0445 & 30.0 & 5.24 & 39 & 10 & 0.89 & 1.46 & 0.43 \\
\hline $26 e$ & & 2-dehydropantoate 2-reductase & $\mathrm{EF} 2445$ & 34.7 & 5.08 & 3 & $1(39)^{g}$ & 1.32 & 1.40 & 0.46 \\
\hline $27^{e}$ & $\begin{array}{l}\text { Transcription and } \\
\text { translation }\end{array}$ & Transcriptional regulator, AraC family & EF0432 & 34.6 & 6.76 & 25 & 7 & 0.91 & 2.64 & 0.18 \\
\hline
\end{tabular}


Table 1: Identified proteins of E. faecalis V583 whose abundance is affected by the presence of $1 \%$ bovine bile-the three columns to the right show the results for cells harvested at three different time points (20,60 and 120 minutes) (Continued)

\begin{tabular}{|c|c|c|c|c|c|c|c|c|c|c|}
\hline 28 & & Cold-shock domain-contain protein & EF2925 & 7.3 & 4.35 & 60 & 5 & 0.97 & 0.33 & 0.37 \\
\hline 29 & & Peptide deformylase & EF3066 & 21.0 & 5.08 & 48 & 6 & 1.15 & 0.77 & 0.5 \\
\hline 30 & & 30 S ribosomal protein S2 & $\mathrm{EF} 2398$ & 29.5 & 5 & 24 & 8 & 2.82 & 1.87 & 0.81 \\
\hline $31^{e}$ & & Ribosomal protein $\mathrm{L} 31$ & EF1171 & 10.1 & 5.57 & 95 & 10 & 1.65 & 0.36 & 0.29 \\
\hline 32 & & Elongation factor $\mathrm{G}$ & EF0200 & 76.6 & 4.8 & 23 & 19 & 0.93 & 0.87 & 1.97 \\
\hline 33 & & $30 S$ ribosomal protein $\mathrm{S} 3$ & EF0212 & 24.4 & 9.8 & 12 & 3 & 0.86 & 2.19 & 0.68 \\
\hline 34 & & $\begin{array}{c}\text { Phenylalanyl-tRNA synthetase subunit } \\
\text { beta }\end{array}$ & EF1116 & 88.8 & 4.76 & 12 & 11 & 0.87 & 0.97 & 2.18 \\
\hline 35 & & Methionyl-tRNA formyltransferase & $\mathrm{EF} 3123$ & 34.3 & 6.06 & 3 & $1(48)^{g}$ & 0.96 & 1.29 & 0.41 \\
\hline 36 & Hypothetical protein & Hypothetical protein EF1967 & EF1967 & 20.7 & 5.98 & 20 & 5 & 0.51 & 0.86 & 0.25 \\
\hline 37 & & Hypothetical protein EF2909 & EF2909 & 12.1 & 4.33 & 52 & 7 & 0.99 & 0.47 & 0.69 \\
\hline 38 & & Hypothetical protein EF2763 & $\mathrm{EF} 2763$ & 12.1 & 4.7 & 43 & 5 & 1.25 & 0.43 & 0.66 \\
\hline 39 & & Hypothetical protein EF2888 & $\mathrm{EF} 2888$ & 8.9 & 4.54 & 42 & 6 & 1.07 & 0.32 & 0.43 \\
\hline $40^{e}$ & & Hypothetical protein EF3184 & EF3184 & 26.4 & 4.86 & 28 & 7 & 0.80 & 0.31 & 0.38 \\
\hline $41^{e}$ & & Hypothetical protein EF3186 & EF3186 & 25.7 & 4.91 & 28 & 8 & 1.44 & 1.80 & 0.44 \\
\hline 42 & & Hypothetical protein EF0123 & EF0123 & 85.5 & 7.23 & 4 & 3 & 1.89 & 2.11 & 0.43 \\
\hline 43 & & Hypothetical protein EF0352 & EF0352 & 29.3 & 6.91 & 4 & $1(61)^{g}$ & 1.44 & 2.18 & 0.48 \\
\hline 44 & & Hypothetical protein EF2174 & $\mathrm{EF} 2174$ & 99.6 & 8.68 & 36 & 33 & 1.54 & 1.41 & 0.32 \\
\hline 45 & & Hypothetical protein EF 2104 & EF2104 & 43.6 & 4.88 & 18 & 6 & 0.82 & 2.36 & 1.17 \\
\hline 46 & Protein fate & Glutamyl-aminopeptidase & EF3037 & 39.4 & 5.68 & 22 & 8 & 0.87 & 1.90 & 1.01 \\
\hline $47^{e}$ & & DnaK protein & EF1308 & 65.5 & 4.59 & 56 & 31 & 1.11 & 1.20 & 2.21 \\
\hline $48^{e}$ & & Heat shock protein GrpE & EF1307 & 20.1 & 4.5 & 26 & 8 & 1.10 & 0.30 & 0.30 \\
\hline $49 f$ & Nucleotid metabolism & Ribose-phosphate pyrophosphokinase & EF3163 & 35.4 & 6.16 & 22 & 9 & 1.21 & 2.5 & 0.47 \\
\hline 50 & & $\begin{array}{l}\text { Inositol-5-monophosphate } \\
\text { dehydrogenase }\end{array}$ & $\mathrm{EF} 3293$ & 52.8 & 5.7 & 50 & 84 & 1.24 & 2.0 & 1.05 \\
\hline $51^{f}$ & & Ribose-phosphate pyrophosphokinase & EF3163 & 35.5 & 6.16 & 15 & 7 & 0.95 & 1.21 & 0.38 \\
\hline 52 & Unknown function & DNAbinding response regulator VicR & EF1193 & 26.9 & 5.17 & 15 & 6 & 0.87 & 1.20 & 0.51 \\
\hline 53 & & Glyoxalase family protein & $\mathrm{EF} 2591$ & 31.7 & 4.85 & 50 & 15 & 1.04 & 0.99 & 0.30 \\
\hline 54 & & PhnA protein & EF1374 & 12.4 & 5.01 & 66 & 6 & 0.9 & 0.55 & 0.47 \\
\hline 55 & & $\begin{array}{l}\text { Oxidoreductase, aldo/keto reductase } \\
\text { family }\end{array}$ & EF1138 & 31.0 & 5.28 & 18 & 5 & 0.97 & 1.22 & 0.44 \\
\hline
\end{tabular}

a The putative function is based on the JCVI Comprehensive Microbial Resource database http://cmr.jcvi.org/tigr-scripts/CMR/CmrHomePage.cgi.

bThe $\mathrm{pl}$ values are theoretical values calculated from the protein sequences

c The coverage shows the percentage of the protein that is covered by the identified peptides.

d Proteins with values over 1 are up-regulated in response to bile, proteins with values below 1 are down-regulated. Values representing a change larger than 1.9 -fold are printed in bold face.

e Proteins that also were shown to be regulated in a transcriptome study of bile responses in E. faecalis V583 [15]; see text for details.

f Note that proteins EF3163 (spots 49 \& 51) and EF1613 (spots 16 \& 19) were identified twice.

9The value in parenthesis shows the probability-based Mowse score for proteins that were identified by only one peptide (in all cases using the LC-LTQ Orbitrap). The Mowse score equals $-10 *$ Log

$(\mathrm{P})$, where $\mathrm{P}$ is the probability that the observed match is a random event; Mowse scores greater than 38 indicate identity or extensive homology $(\mathrm{p}<0.05)$. 


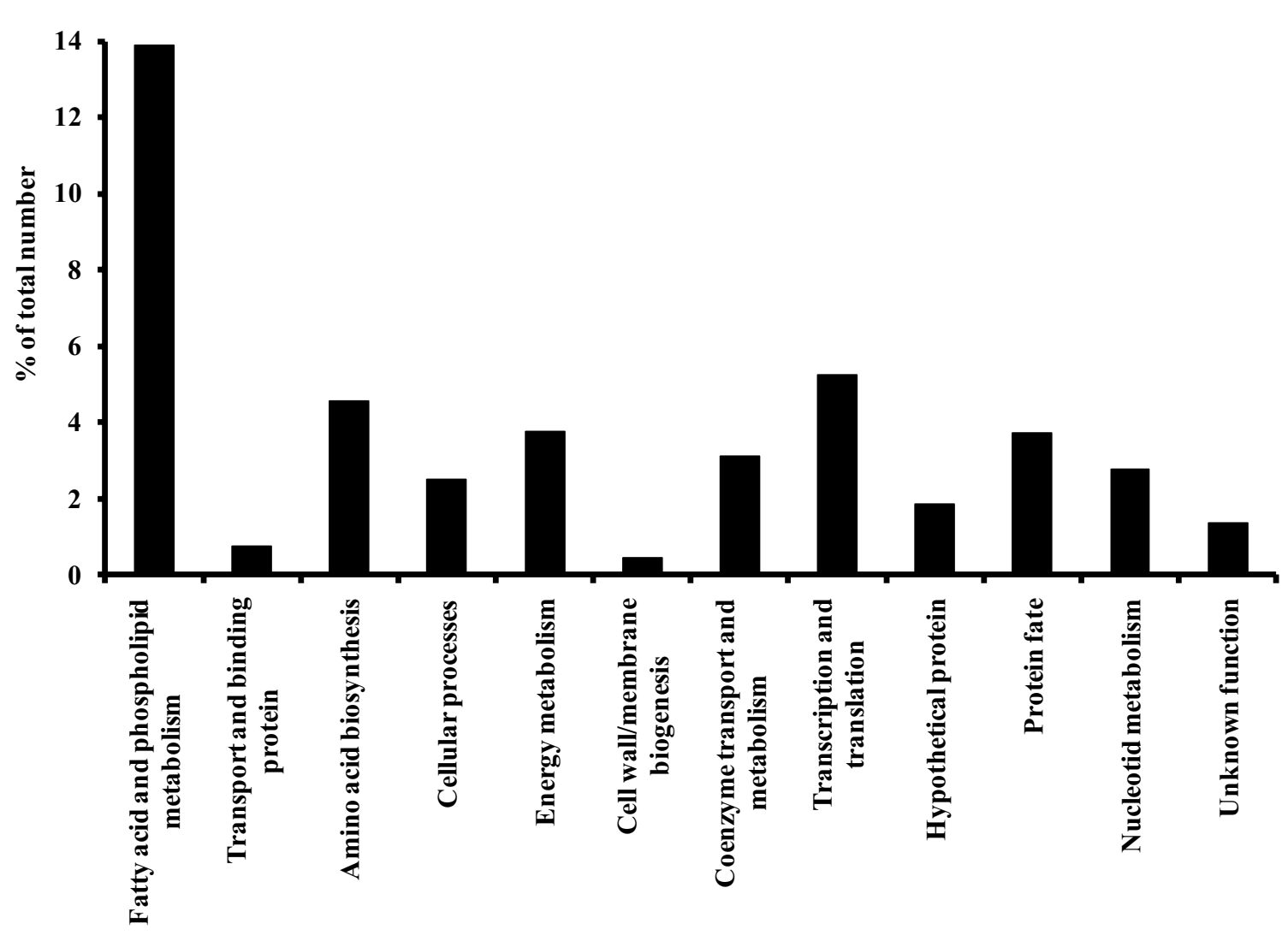

Figure 2 Relative abundance of identified regulated proteins in E. faecalis V583. Proteins (53 in total) are grouped according to their functional class as defined by JVCl http://cmr.jcvi.org/tigr-scripts/CMR/CmrHomePage.cgi. The values for each class represent the fraction (in \%) of the total expected proteome in that class that was identified in the present study.

to be significantly regulated in the present study. This difference may be due to the fact that the bile salt concentrations used in these previous studies were lower $(0.08$ or $0.3 \%$ ). Furthermore, these studies used another E. faecalis strain which is less resistant to bile than the V583 strain.

The 2D-PAGE experiments provide information on changes in protein levels only and do not provide direct information on the underlying gene expression levels (mRNA production levels). The previous transcriptional study [15] on the same bacterium and under the same conditions, revealed 308 genes whose expression was affected by bile during the time course experiment, representing about $10 \%$ of the genes in the genome. The fraction of regulated genes in each functional class varied between $5.6 \%$ and $16.7 \%$ of the total number of genes per class, with the exception of genes involved in the fatty acid- and phospholipid metabolism, of which $41.7 \%$ were found to be regulated [15]. Compared to the transcriptome study, the present proteome study revealed fewer regulated genes/proteins; we identified about $2 \%$ of the total proteome and the representation of each functional class varied between $0.5 \%$ and $5.3 \%$ (Fig. 2). Again, proteins involved in fatty acid- and phospholipid metabolism formed the exception, since $14.0 \%$ of these were found to be regulated. The lower number of genes/proteins found in the proteome study is not only due to sensitivity and dynamic range issues but also to the fact that insoluble proteins and the major part of proteins that are secreted out of the cell are not expected to be found in the cytoplasmic fraction. The transcriptome and proteome data correlate reasonably well for 11 of the 19 genes/proteins that were identified with both methods (Fig. 4). Not unexpectedly, in several cases changes in protein levels lag behind changes in RNA levels. Several proteins show clear discrepancies between the proteome and the transcriptome data and in almost all of these cases an upregulation of the mRNA is not accompanied by higher protein levels (EF1499, EF2151, EF1171, EF0020, EF3184, EF3186). One may speculate that other regulatory mechanisms come into play, such as translational regulation or specific protein degradation. Two of these genes (EF3184, EF3186) are part of an operon consisting of five genes, of which four encode proteins with putative N-terminal signal-peptides. None of these proteins show homology with other proteins with known function. Clearly, the fact that these proteins are secreted may lead to discrepancies 


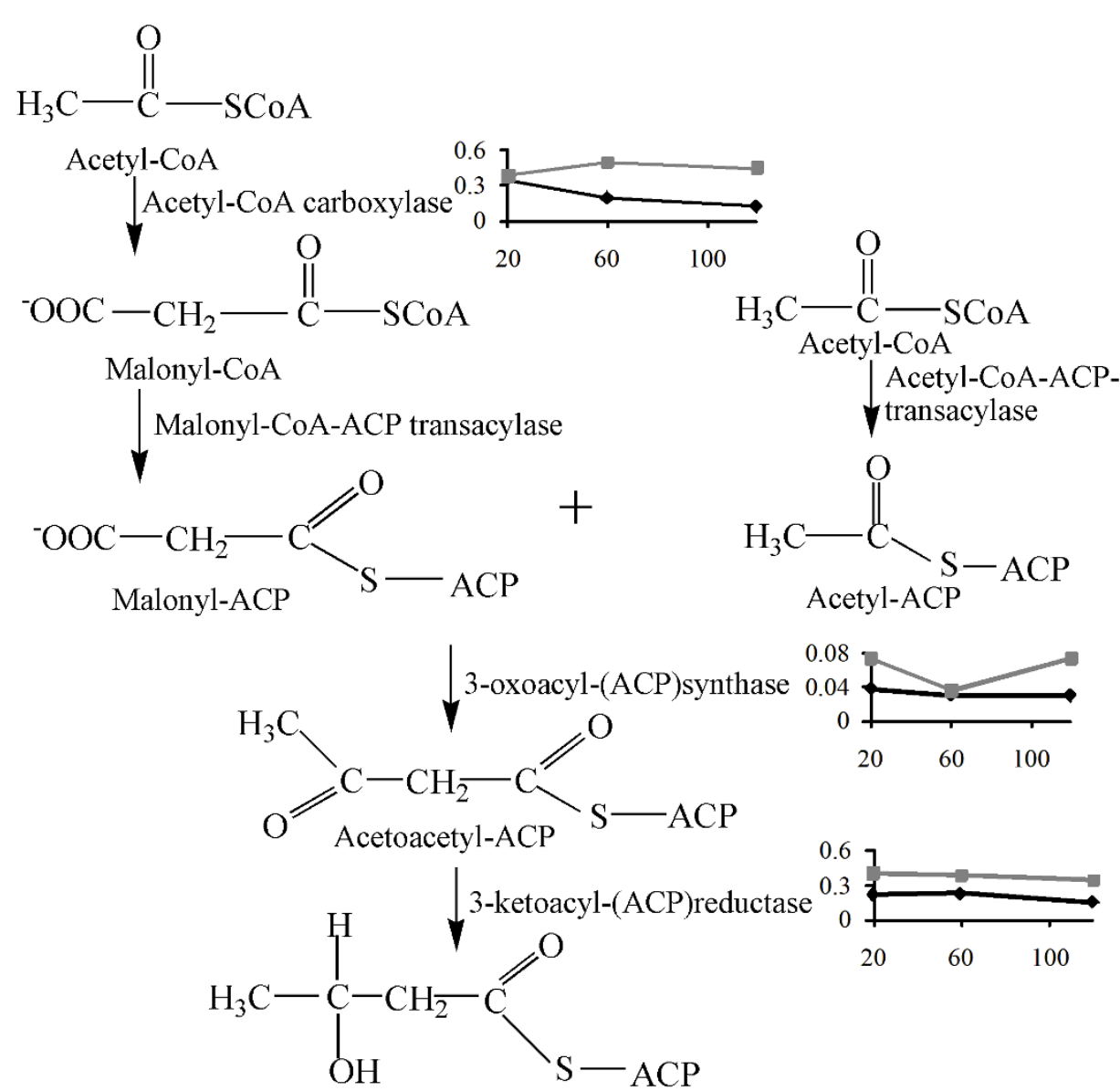

D-3-Hydroxy-butanoyl-ACP<smiles>C/C=C/C(=O)S[Mg]</smiles>

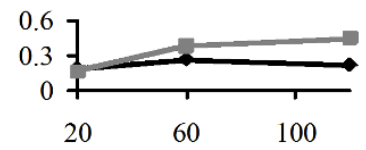

But-2-enoyl-ACP

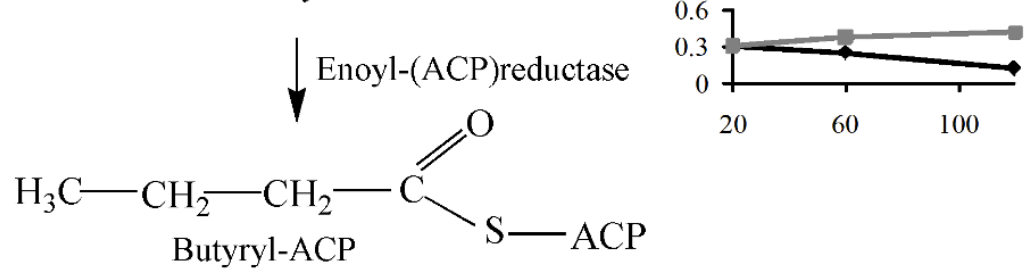

Figure 3 Overview of fatty acid biosynthesis http://www.genome.jp/kegg/pathway/map/map00061.html and regulation of key enzymes. The starting reactant is acetyl-CoA. The principal reaction products of the fatty acid biosynthesis are straight-chain C16 and C18 fatty acids, which can be used in the synthesis and the repair of damaged phospholipid membranes. The resulting fatty acids are therefore important constituents of the cell membrane. The graphs to the right show the development of protein abundance during the time course experiment. The grey line corresponds to protein produced in bacteria grown in media without bovine bile, while the black line corresponds to bacteria grown in media containing $1 \%$ bovine bile. The $x$-axis indicates the time (minutes) and the $y$-axis the spot intensity (normalized raw spot volume) of the protein as a mean value of the parallels. The lines are drawn for illustration purposes only, connecting the three time points that were analyzed (20,60 and 120 minutes). 
EF0282

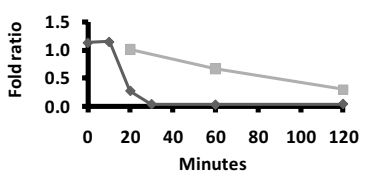

EF0283

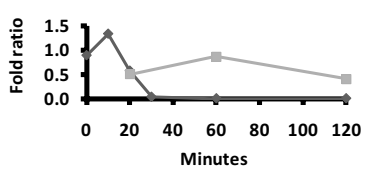

EF0105

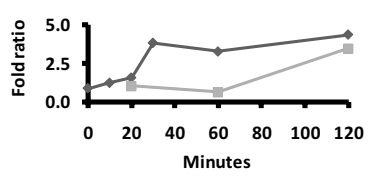

EF2556

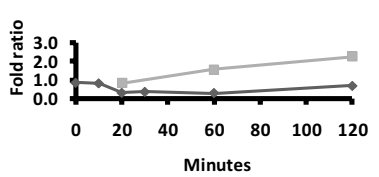

EF2445

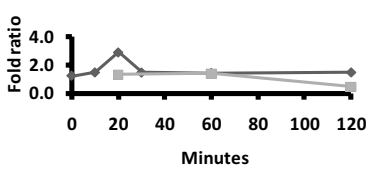

EF3184

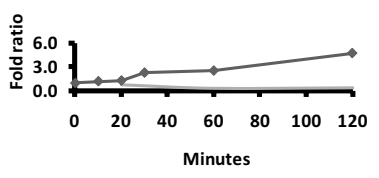

EF1307

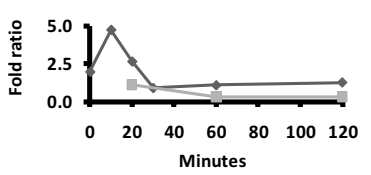

EF2879

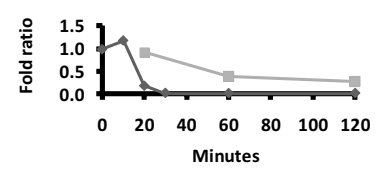

EF2881

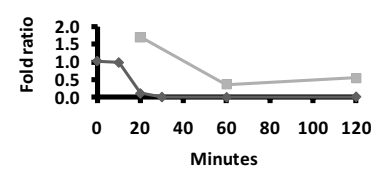

EF0634

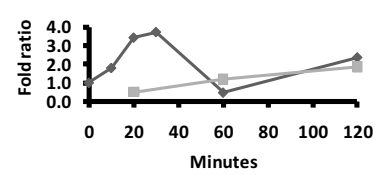

EF1499

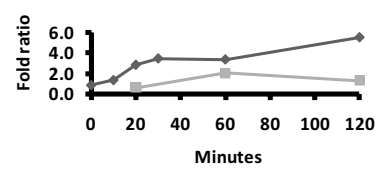

EF0432

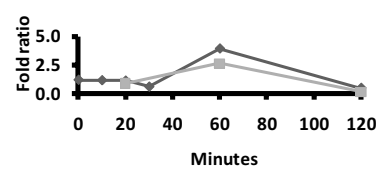

EF3186

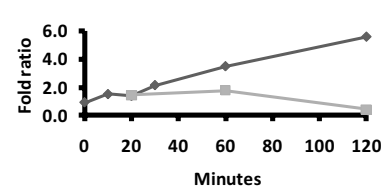

EF0284

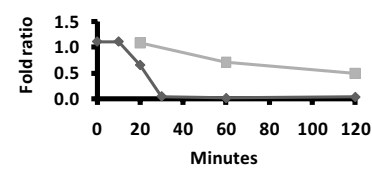

EF0020

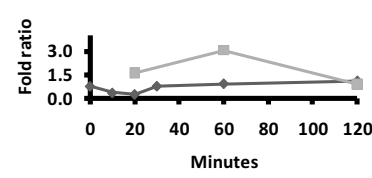

EF0174

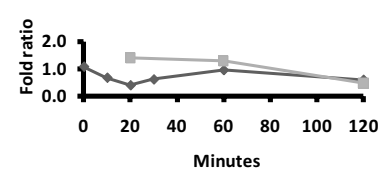

EF2151

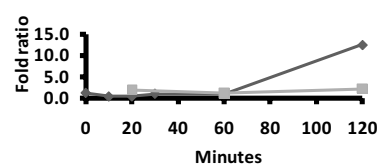

EF1171

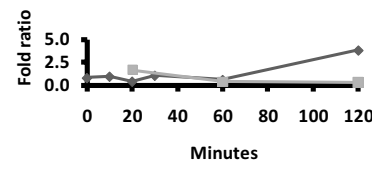

EF1308

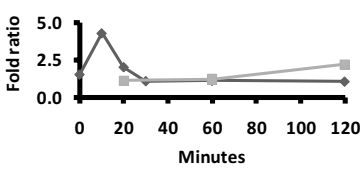

Figure 4 Expression-profiles of the 19 proteins that were found to be regulated by bile at both the transcriptome [15] and the proteome level. The dark lines show the data from the transcriptome study, while the grey lines show the data from the present proteome study. The $y$-axis indicates the fold ratio, while the $x$-axis shows the culturing time in minutes. 
between the transcriptome data and data for the intracellular proteome.

Proteins related to general bacterial stress responses primarily occur in the functional classes "Protein fate" and "Other cellular processes". We identified two general stress proteins, the chaperone DnaK (EF1308) and a heatshock protein GrpE (EF1307). It has previously been shown that a number of stress factors, including bile, have an effect of the expression of DnaK and/or GrpE in Enterococcus and other Gram-positive bacteria $[16,18,29,30]$. Three of the four identified proteins in "Other cellular processes" are related to stress; glutathione reductase (EF3270), Dps (DNA protecting protein under starved conditions; EF3233), and a putative general stress protein of unknown function (EF1744). Whereas EF3233 and EF1744 both are down-regulated, the glutathione reductase, a cellular antioxidant involved in oxidative defence, is significantly up-regulated after 20 minutes, indicating fast response to the deleterious effects of bovine bile. The fourth protein, DivIVA (EF1002) is strongly up-regulated after 120 minutes. DivIVA plays a crucial role in cell division [31]. Recently, it has been shown that DivIVA may also play a role in managing oxidative stress [32]. Other (transcriptome) studies have also shown that expression of general stress proteins is influenced by bile acids [12,13].

The five proteins involved in the fatty acid biosynthesis affected by bile correspond to $14 \%$ of the total number of proteins in the functional class of "Fatty acid and phospholipid metabolism", meaning that this class is clearly overrepresented among the regulated proteins (Fig. 2). These five proteins, as well as nine of the ten additional affected genes within this class identified in the previous transcriptome study [15], were all down-regulated upon exposure to bile and the down-regulation increased during the time course experiment (Table 1). All five proteins identified here are involved in fatty acid biosynthesis (Fig. 3 ), and our data thus clearly show that this process is down-regulated in response to bile. Previous studies have suggested that bile changes the membrane surface as a response to the actions of bile $[7,33]$, but so far, there is limited proteomic data that has supported this notion. Proteomic studies of bile stress in B. animalis [28] and $P$. freudenreihii [22] each led to the identification of only one (down-regulated) protein in the "Fatty acid and phospholipid metabolism" class. Interestingly, a recent transcriptome study showed that expression of genes involved in fatty acid and phospholipid biosynthesis was up-regulated in E. faecalis V583 grown on blood [34]. This indicates that the down-regulation of fatty acid biosynthesis is a bile-specific response and that the bacteria respond differently when grown in blood.

Eight regulated proteins play a role in energy metabolism, representing $4 \%$ of this functional class (Fig. 2). The proteins are involved in different pathways, including glycolysis (EF 0195, EF1046, EF1961), pentose phosphate pathway (EF0174), pyruvate metabolism (EF1613), oxidative phosphorylation (EF2556, EF1499), and the electron transport chain (EF1405). Proteins identified in the first two pathways are members of the carbohydrate metabolism, and most of these proteins were down-regulated in contrast to what has been observed in other studies regarding bile stress [23,27]. Interestingly, a V-type ATPase (EF1499), which couples hydrolysis of ATP to the translocation of protons across bacterial membranes, was up-regulated. Maintenance of the proton motive force is an important factor during bile stress, because it contributes to sustain cellular homeostasis [6]. Pyruvate kinase (EF1046), which converts phosphoenolpuruvate to pyruvate, and formate acetyltransferase (EF1613), which is responsible for the transfer of an acetyl group from acetyl-CoA to formate, yielding $\mathrm{CoA}$ and pyruvate, were up-regulated. Pyruvate is a metabolic key molecule that can be used in a number of different reactions to increase the ATP levels. The combined up-regulation of formate acetyltransferase and down-regulation of fatty acid biosynthesis genes indicate that bile stress changes the flux of acetyl-CoA from fatty acid synthesis towards generation of ATP.

Three transporter and binding proteins were identified (EF0020, EF0709 and EF0912). The IIAB component of a mannose-specific phosphotransferase system (PTS; EF0020) was strongly up-regulated. Interestingly, there are studies showing that this type of transporter is important for the survival of saprophytic and pathogenic bacteria on the mucosal surfaces of animals [35]. Thus, it is conceivable that these proteins are also important for adapting to bile-rich environments. Both the phosphocarrier protein $\mathrm{HPr}$ (EF0709) and the peptide ABC transporter (EF0912) were down regulated. The phosphocarrier protein HPr is a component of the phosphoenolpyruvate-dependendent PTS, which is a major carbohydrate transport system in bacteria. The mechanism involves the transfer of a phosphoryl group from phosphoenolpyruvate which are formed by the actions of enolase (EF1961) in the glycolysis. The fact that both enolase (EF1961), and phophocarrier protein HPr (EF0709) are down- regulated, correlates with the down-regulation of other proteins involved in carbohydrate metabolism (see above). In bifidobacteria, bile stress resulted in the up-regulation of some sugar transport proteins [23,28]. This may indicate that E. faecalis V583 and bifidobacteria use different strategies in how to handle bile.

Four of the identified proteins have unknown functions, and another ten are hypothetical. Most of these fourteen "unknown" proteins were down-regulated by bile. Only two of these proteins (EF3184, EF3186) were also found to be down-regulated in the transcriptome 
study [15]. A Blast search with the hypothetical proteins did not reveal significant sequence similarity with hypothetical proteins found in studies of bile responses in other Gram positive bacteria. It must be emphasized that several of these hypothetical proteins are strongly regulated, indicating that they may play important roles in the bile stress response.

Two of the proteins that were classified as proteins with unknown function according to JCVI, are a DNA binding response regulator (EF1193) that is part a two-component regulatory system (EF1194 is a kinase), and an oxidoreductase (EF1138). Two-component regulatory systems are important for responding to environmental changes, whereas the oxidoreductase could play a role in bile modification [13].

Bile salt hydrolases (BSH) catalyze the deconjugation of bile salts, which may be a detoxification mechanism [36]. Experimental data suggests that BSHs indeed play a role in bile tolerance in Gram-positive bacteria [37-39]. The genome of $E$. faecalis contains two genes that putatively encode for BSHs. However, in response to bile no effect on the BSH expression was observed, neither at the transcriptome [15] nor at the proteome level, which is in agreement with other studies on bile-induced gene regulation in Gram-positive bacteria [13,27]. Several gene-bygene studies indicate that at least part of the known (putative) $b s h$-genes play minor roles in the bile response of lactobacilli [40-42]. All in all, the role of BSHs in bile responses remains somewhat elusive.

\section{Conclusions}

The present study showed that of approximately 500 observed proteins, 53 proteins were significantly regulated in response to bile which provides several leads for further analyses of how E. faecalis responds to bile and, perhaps, to stress in general. The clear bile-induced regulation of fatty acid biosynthesis shown at both the proteome and transcriptome level in E. faecalis V583 has not been shown previously in Gram-positive bacteria, including enterococci, bifidobacteria and lactobacilli. Proteins involved in fatty acid metabolism were overrepresented among the regulated proteins. In addition, several hypothetical proteins also stand out as targets for further work, including EF1967 and EF2104, which are both abundant and clearly regulated. Such further work is currently in progress in our laboratories.

\section{Additional material}

Additional file $\mathbf{1}$ Figure $\mathbf{S} \mathbf{1}$. Silver stained 2D-electrophoresis gels of the intracellular proteome of E. faecalis V583 grown in liquid BHI with and without $1 \%$ bovine bile. The gels show protein extracts from cells harvested 20, 60 or 120 minutes after the addition of bile. The numbered spots indicate proteins that were identified as being regulated in response to bile stress, using statistical methods and cut-off values described in the main manuscript.
Competing interests

The authors declare that they have no competing interests.

\section{Authors' contributions}

IFN, VGHE and GM developed the initial concept for this study. LAB, EMF, IFN, VGHE and GM participated in experimental design. LAB carried out the $2 D$ electrophoresis and did the mass spectrometric analyses. EVK and HS participated in the set-up and standardization of the 2D-electrophoresis. $L A B$ and EMF did the statistical analyses and the initial interpretation of the results. $L A B$, VGHE and GM drafted the paper, implementing contributions from all other authors. All authors have read, corrected and approved the final manuscript.

\section{Acknowledgements}

This work was supported by grants 183627 and 183637 from the Norwegian Research Council. Thanks to Morten Skaugen, and Øyvind Busk for technical help during the MS-analysis. We also thank Bernd Thiede at the Biotechnology Centre of Oslo for LC-LTQ Orbitrap-MS analyses.

\section{Author Details}

1Department of Chemistry, Biotechnology and Food Science, Norwegian University of Life Sciences, Chr. M. Falsensvei 1, N-1432 Ås, Norway and 2Nofima Mat AS, Norwegian Institute of Food, Fisheries and Aquaculture Research, N-1430 Ås, Norway

Received: 4 March 2010 Accepted: 25 June 2010

Published: 25 June 2010

\section{References}

1. Paulsen IT, Banerjei L, Myers GS, Nelson KE, Seshadri R, Read TD, Fouts DE, Eisen JA, Gill SR, Heidelberg JF, et al:: Role of mobile DNA in the evolution of vancomycin-resistant Enterococcus faecalis. Science 2003, 299:2071-2074.

2. Tacconelli E, Cataldo MA: Vancomycin-resistant enterococci (VRE): transmission and control. Int J Antimicrob Agents 2008, 31:99-106.

3. Cetinkaya Y, Falk P, Mayhall CG: Vancomycin-resistant enterococci. Clin Microbiol Rev 2000, 13:686-707.

4. Fisher K, Phillips C: The ecology epidemiology and virulence of Enterococcus. Microbiology 2009, 155:1749-1757.

5. Rince A, Le Breton Y, Verneuil N, Giard JC, Hartke A, Auffray Y: Physiological and molecular aspects of bile salt response in Enterococcus faecalis. Int J Food Microbiol 2003, 88:207-213.

6. Begley M, Gahan CG, Hill C: The interaction between bacteria and bile. FEMS Microbiol Rev 2005, 29:625-651.

7. Taranto MP, Fernandez Murga ML, Lorca G, de Valdez GF: Bile salts and cholesterol induce changes in the lipid cell membrane of Lactobacillus reuteri. J Appl Microbiol 2003, 95:86-91.

8. Ruiz L, Sanchez B, Ruas-Madiedo P, de Los Reyes-Gavilan CG, Margolles A: Cell envelope changes in Bifidobacterium animalis ssp. lactis as a response to bile. FEMS Microbiol Lett 2007, 274:316-322.

9. Bron PA, Marco M, Hoffer SM, Van Mullekom E, de Vos WM, Kleerebezem $\mathrm{M}$ : Genetic characterization of the bile salt response in Lactobacillus plantarum and analysis of responsive promoters in vitro and in situ in the gastrointestinal tract. J Bacterio/ 2004, 186:7829-7835.

10. Kristoffersen SM, Ravnum S, Tourasse NJ, Okstad OA, Kolsto AB, Davies W: Low concentrations of bile salts induce stress responses and reduce motility in Bacillus cereus ATCC 14579. J Bacteriol 2007, 189:5302-5313.

11. Gueimonde M, Garrigues C, van Sinderen D, de los Reyes-Gavilan CG, Margolles A: Bile-inducible efflux transporter from Bifidobacterium longum NCC2705, conferring bile resistance. Appl Environ Microbiol 2009, 75:3153-3160.

12. Whitehead K, Versalovic J, Roos S, Britton RA: Genomic and genetic characterization of the bile stress response of probiotic Lactobacillus reuteri ATCC 55730. App/ Environ Microbiol 2008, 74:1812-1819.

13. Pfeiler EA, Azcarate-Peril MA, Klaenhammer TR: Characterization of a novel bile-inducible operon encoding a two-component regulatory system in Lactobacillus acidophilus. J Bacteriol 2007, 189:4624-4634.

14. Bron PA, Molenaar D, de Vos WM, Kleerebezem M: DNA micro-arraybased identification of bile-responsive genes in Lactobacillus plantarum. J App/ Microbiol 2006, 100:728-738.

15. Solheim M, Aakra A, Vebo H, Snipen L, Nes IF: Transcriptional responses of Enterococcus faecalis V583 to bovine bile and sodium dodecyl sulfate. Appl Environ Microbiol 2007, 73:5767-5774. 
16. Flahaut $S$, Frere J, Boutibonnes $P$, Auffray $Y$ : Comparison of the bile salts and sodium dodecyl sulfate stress responses in Enterococcus faecalis. Appl Environ Microbiol 1996, 62:2416-2420.

17. Flahaut S, Hartke A, Giard JC, Benachour A, Boutibonnes P, Auffray Y: Relationship between stress response towards bile salts acid and heat treatment in Enterococcus faecalis. FEMS Microbiol Lett 1996, 138:49-54.

18. Giard JC, Laplace JM, Rince A, Pichereau V, Benachour A, Leboeuf C, Flahaut S, Auffray Y, Hartke A: The stress proteome of Enterococcus faecalis. Electrophoresis 2001, 22:2947-2954.

19. Sahm DF, Kissinger J, Gilmore MS, Murray PR, Mulder R, Solliday J, Clarke B: In vitro susceptibility studies of vancomycin-resistant Enterococcus faecalis. Antimicrob Agents Chemother 1989, 33:1588-1591.

20. Shevchenko A, Wilm M, Vorm O, Mann M: Mass spectrometric sequencing of proteins silver-stained polyacrylamide gels. Anal Chem 1996, 68:850-858.

21. Berth M, Moser FM, Kolbe M, Bernhardt J: The state of the art in the analysis of two-dimensional gel electrophoresis images. App/Microbiol Biotechnol 2007, 76:1223-1243.

22. Leverrier P, Dimova D, Pichereau V, Auffray Y, Boyaval P, Jan G: Susceptibility and Adaptive Response to Bile Salts in Propionibacterium freudenreichii: Physiological and Proteomic Analysis. Appl Environ Microbiol 2003, 69:3809-3818.

23. Sanchez B, Champomier-Verges MC, Anglade P, Baraige F, de Los ReyesGavilan CG, Margolles A, Zagorec M: Proteomic analysis of global changes in protein expression during bile salt exposure of Bifidobacterium longum NCIMB 8809. J Bacterio/ 2005, 187:5799-5808.

24. Moen B, Oust A, Langsrud O, Dorrell N, Marsden GL, Hinds J, Kohler A, Wren BW, Rudi K: Explorative multifactor approach for investigating global survival mechanisms of Campylobacter jejuni under environmental conditions. Appl Environ Microbiol 2005, 71:2086-2094.

25. Langsrud Ø: Rotation tests. Statistics and computing 2005, 15:53-60.

26. Rappsilber J, Ishihama Y, Mann M: Stop and go extraction tips for matrixassisted laser desorption/ionization, nanoelectrospray, and LC/MS sample pretreatment in proteomics. Analyt Chem 2003, 75:663-670.

27. Lee K, Lee HG, Choi YJ: Proteomic analysis of the effect of bile salts on the intestinal and probiotic bacterium Lactobacillus reuteri. J Biotechnol 2008, 137:14-19.

28. Sanchez B, Champomier-Verges MC, Stuer-Lauridsen B, Ruas-Madiedo P, Anglade P, Baraige F, de los Reyes-Gavilan CG, Johansen E, Zagorec M, Margolles A: Adaptation and response of Bifidobacterium animalis subsp. lactis to bile: a proteomic and physiological approach. Appl Environ Microbiol 2007, 73:6757-6767.

29. Leverrier P, Vissers JP, Rouault A, Boyaval P, Jan G: Mass spectrometry proteomic analysis of stress adaptation reveals both common and distinct response pathways in Propionibacterium freudenreichii. Arch Microbiol 2004, 181:215-230.

30. Schmidt G, Zink R: Basic features of the stress response in three species of bifidobacteria: B. longum, B. adolescentis, and B. breve. Int J Food Microbiol 2000, 55:41-45.

31. Ramirez-Arcos S, Liao M, Marthaler S, Rigden M, Dillon JA: Enterococcus faecalis divIVA: an essential gene involved in cell division, cell growth and chromosome segregation. Microbiology 2005, 151:1381-1393.

32. Mukherjee P, Sureka K, Datta P, Hossain T, Barik S, Das KP, Kundu M, Basu J: Novel role of Wag31 in protection of mycobacteria under oxidative stress. Mol Microbiol 2009, 73:103-119.

33. Ruiz L, Coute Y, Sanchez B, de los Reyes-Gavilan CG, Sanchez JC, Margolles $A$ : The cell-envelope proteome of Bifidobacterium longum in an in vitro bile environment. Microbiology 2009, 155:957-967.

34. Vebø HC, Snipen L, Nes IF, Brede DA: The transcriptome of the nosocomial pathogen Enterococcus faecalis V583 reveals adaptive responses to growth in blood. PLoS One 2009, 4:e7660.

35. Zuniga M, Comas I, Linaje R, Monedero V, Yebra MJ, Esteban CD, Deutscher J, Perez-Martinez G, Gonzalez-Candelas F: Horizontal gene transfer in the molecular evolution of mannose PTS transporters. Mol Biol Evol 2005, 22:1673-1685.

36. Begley M, Hill C, Gahan CG: Bile salt hydrolase activity in probiotics. App/ Environ Microbiol 2006, 72:1729-1738.

37. Jones BV, Begley M, Hill C, Gahan CG, Marchesi JR: Functional and comparative metagenomic analysis of bile salt hydrolase activity in the human gut microbiome. Proc Natl Acad Sci USA 2008, 105:13580-13585.
38. Elkins CA, Moser SA, Savage DC: Genes encoding bile salt hydrolases and conjugated bile salt transporters in Lactobacillus johnsonii 100-100 and other Lactobacillus species. Microbiology 2001, 147:3403-3412.

39. Tanaka H, Doesburg K, Iwasaki T, Mierau I: Screening of lactic acid bacteria for bile salt hydrolase activity. J Dairy Sci 1999, 82:2530-2535.

40. Lambert JM, Bongers RS, de Vos WM, Kleerebezem M: Functional analysis of four bile salt hydrolase and penicillin acylase family members in Lactobacillus plantarum WCFS1. Appl Environ Microbiol 2008 , 74:4719-4726.

41. McAuliffe O, Cano RJ, Klaenhammer TR: Genetic analysis of two bile salt hydrolase activities in Lactobacillus acidophilus NCFM. Appl Environ Microbiol 2005, 71:4925-4929.

42. Fang F, Li Y, Bumann M, Raftis EJ, Casey PG, Cooney JC, Walsh MA, O'Toole PW: Allelic variation of bile salt hydrolase genes in Lactobacillus salivarius does not determine bile resistance levels. J Bacteriol 2009, 191:5743-5757.

doi: $10.1186 / 1477-5956-8-37$

Cite this article as: Bøhle et al., Identification of proteins related to the stress response in Enterococcus faecalis V583 caused by bovine bile Proteome Science 2010, 8:37

\section{Submit your next manuscript to BioMed Central and take full advantage of:}

- Convenient online submission

- Thorough peer review

- No space constraints or color figure charges

- Immediate publication on acceptance

- Inclusion in PubMed, CAS, Scopus and Google Scholar

- Research which is freely available for redistribution
C) BioMed Central 